\title{
Levamisole-Induced Occlusive Necrotizing Vasculitis of the Ears After Use of Cocaine Contaminated with Levamisole
}

\author{
Jennie A. Buchanan • Jody A. Vogel • \\ Aaron M. Eberhardt
}

Published online: 12 June 2010

(C) American College of Medical Toxicology 2010

\begin{abstract}
Based on the best available data, approximately 2.1 million Americans use illicit cocaine each month; for the last several months, $30 \%$ of that cocaine has been "cut" with a veterinary pharmaceutical, levamisole. Levamisole can cause agranulocytosis, leaving patients susceptible to fulminate and opportunistic infections and also can cause a debilitating cutaneous necrotizing vasculitis. In this manuscript, we describe a case and provide an image of levamisole-induced necrotizing vasculitis of the ears.
\end{abstract}

Keywords Levamisole $\cdot$ Vasculitis $\cdot$ Cocaine $\cdot$ Necrotizing

\section{Question/Scenario}

A previously healthy adult male presented to the emergency department in severe pain with bilateral, purple discoloration of his ears over the past $12 \mathrm{~h}$. He reported a history of nasal cocaine use (nine hours prior) and denied recent intravenous drug use. He was in moderate discomfort with

\footnotetext{
J. A. Buchanan $(\bowtie) \cdot$ J. A. Vogel $\cdot$ A. M. Eberhardt

Department of Emergency Medicine,

Denver Health and Hospital Authority,

777 Bannock St. MC 0108,

Denver, CO, USA

e-mail: Jennie.Buchanan3@dhha.org
}

\section{J. A. Buchanan}

Rocky Mountain Poison and Drug Center,

Denver Health and Hospital Authority,

777 Bannock St. MC 0108,

Denver, CO 80204, USA

J. A. Buchanan · J. A. Vogel - A. M. Eberhardt University of Colorado Denver School of Medicine,

Aurora, CO, USA stable vital signs. On physical examination he had bilateral necrosis of his ears (Figs. 1, and 2) as well as left upper arm and right second toe discoloration. The remainder of his physical examination was normal with notable absence of a cardiac murmur. He had a normal chemistry panel and lactate, low white blood cell count $(1,900$ cells $/ \mathrm{mm} 3)$, and cocaine metabolites on urine toxicology screen. The patient received $10 \mathrm{mg}$ of subcutaneous phentolamine to both ears without improvement. A cardiac echo was negative for endocarditis. Toxicology, Rheumatology, and ENT were consulted. What was the likely etiology of this patient's presentation?

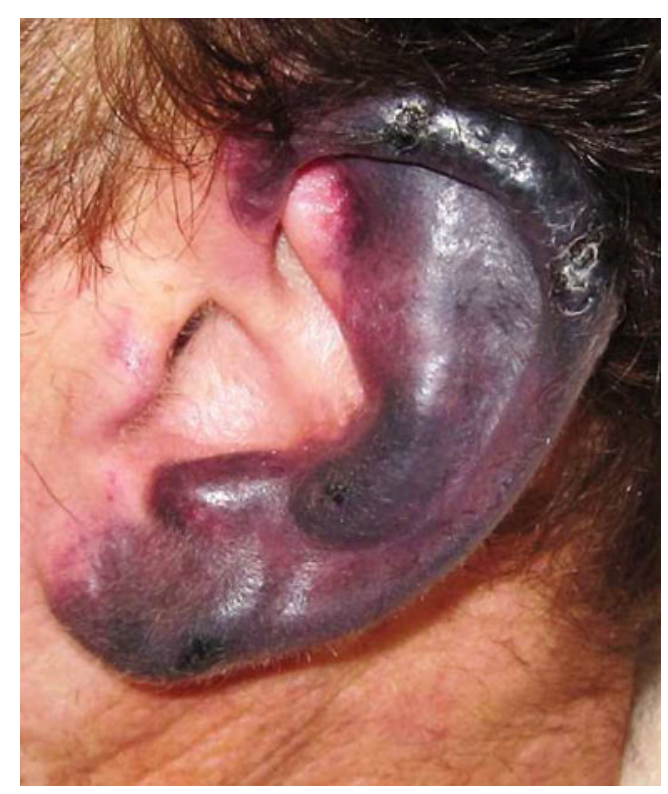

Fig. 1 Image showing necrosis of the patient's left ear 


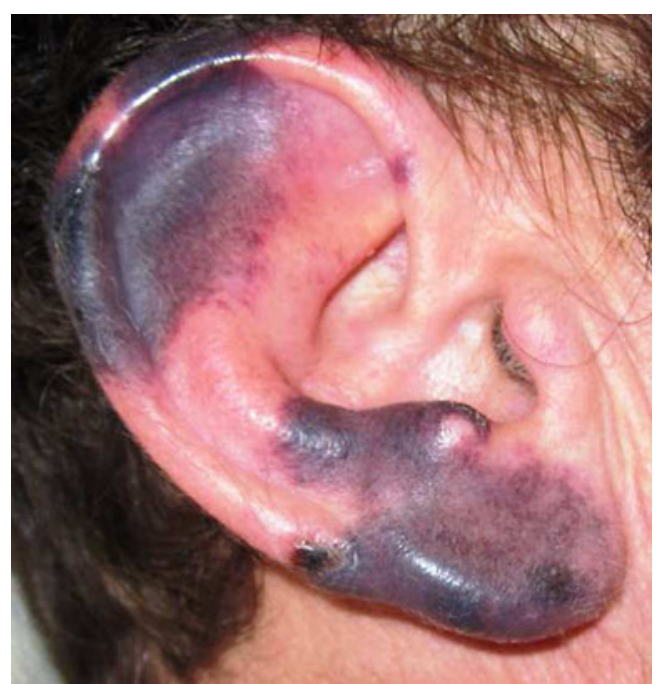

Fig. 2 Image showing necrosis of the patient's right ear

\section{Answer/Discussion}

Given the prevalence of levamisole found in cocaine in the Denver area, the patient's low WBC, and historical evidence of levamisole-induced occlusive necrotizing vasculitis, a levamisole level was sent. Qualitative urine levamisole was positive. The patient was discharged with a diagnosis of levamisole-induced occlusive necrotizing vasculitis. Levamisole was originally developed as an antihelminthic agent and is approved as adjuvant chemotherapy, for the treatment of colon cancer. Levamisole-induced occlusive necrotizing vasculitis is an uncommon side-effect of levamisole. Reports of ear lobe and cutaneous necrosis have been reported in the literature after levamisole was used to treat various cancers, nephrotic syndrome, and rheumatologic disorders [1, 2]. Treatment is primarily supportive with cessation of the offending agent; however, steriods have been used in some cases with success.

\section{References}

1. Menni S, Pistritto G, Gianotti R et al (1997) Ear lobe bilateral necrosis by levamisole-induced occlusive vasculitis in a pediatric patient. Ped Derm 14(6):477-479

2. Rongioletti F, Ghio L, Ginevri F et al (1999) Purpura of the ears: a distinctive vasculopathy with circulating autoantibodies complicating long-term treatment with levamisole in children. $\mathrm{Br} \mathrm{J}$ Dermatol $140: 948-951$ 